\title{
ARTE, ANTROPOLOGÍA Y MUSEOS: ORIENTACIONES POSCOLONIALES EN LOS ESTADOS UNIDOS ${ }^{1}$
}

\author{
SALLY PRICE ${ }^{2}$ \\ www.richandsally.net
}

Resumen: A lo largo del último medio siglo, los cambios en la realidad política, cultural, demográfica y académica de los Estados Unidos han contribuido a una significativa reorientación en la representación museológica de la diferencia. Este texto se teje dentro y fuera de esos diferentes contextos con el fin de explorar algunos de los modos en que la antropología y la historia del arte han sido empujadas en nuevas direcciones, con importantes consecuencias para los museos y sus públicos. A partir de los cambios en la ética del trabajo de campo etnográfico, traza los cambios en la naturaleza de la escritura etnográfica, el uso creciente por parte de la historia del arte de materiales que alguna vez fueron del dominio exclusivo de la antropología, la participación de voces nativas en ambas disciplinas, y la tendencia hacia una antropología colaborativa y el co-comisariado en exposiciones museísticas.

Palabras Clave: antropología, historia del arte, museos, colaboración, ética, Estados Unidos.

АвSTRACT: Over the past half-century, changes in political, cultural, demographic, and academic realities in the United States have contributed to a significant reorientation in the museological representation of difference. This essay weaves in and out of these different contexts in order to explore some of the ways in which anthropology and art history have been nudged in new directions, with important consequences for museums and their publics. Beginning with shifts in the ethics of field ethnography, it traces changes in the nature of ethnographic writing, the growth of art historical interest in materials that were once the sole domain of anthropology, the involvement of native voices in both disciplines, and the trend toward collaborative anthropology and co-curated museum exhibitions.

KeYwords: anthropology, art history, museums, collaboration, ethics, United States.

1 Este texto ha sido traducido por Lorenzo Mariano Juárez.

2 sallyprice123@gmail.com 
«Hasta 1980, la mayoría de los museos eran lugares bastante aburridos y anticuados donde poco sucedía, pero desde entonces se han convertido en semilleros de controversia y pararrayos para la crítica cultural». (Shepard Krech III, Museums, Voices, Representations)

A lo largo del último medio siglo, los cambios en la realidad política, cultural, demográfica y académica de los Estados Unidos han contribuido a una significativa reorientación en la representación museológica de la diferencia. Este texto se teje dentro y fuera de esos diferentes contextos con el fin de explorar algunos de los modos en que la antropología y la historia del arte han sido empujadas en nuevas direcciones, con importantes consecuencias para los museos y sus públicos ${ }^{3}$. Comienzo en la década de los sesenta, un momento crucial que, como George Stocking ha argumentado, marcó el final de "periodo clásico» de la antropología (1992:342-72).

A grandes rasgos, Estados Unidos se encontraba plagado de indicios embrionarios de lo que serían modestos cambios respecto a la antigua práctica de privilegiar públicamente a hombres, euroamericanos, heterosexuales, sin discapacidades físicas y económicamente bien situados. Las demandas del movimiento por los Derechos Civiles avanzaban lentamente, sobre todo a partir de la «1963 March on Washington» (Marcha de 1963 en Washington) y el Acta de Derechos Civiles de 1965; el movimiento Black Power acaparaba portadas a diario; el movimiento feminista iba más allá de su temprana atención por el derecho al voto en favor de una demanda de mayor calado por la reorganización de los roles de las mujeres en la sociedad; las protestas contra la guerra de Vietnam y la agenda imperialista - que fue vista como conductora de la misma—, estaban saliendo a la luz; y la lucha por los derechos de los homosexuales y los derechos de los discapacitados comenzaba a prender. La creciente visibilidad y el activismo de «contra-culturas» de diversa condición tuvieron importantes implicaciones tanto para la práctica de la antropología como para la representación hegemónica de «los otros» en los museos.

\footnotetext{
3 Mucho de lo relevante queda inevitablemente fuera de esta reflexión sobre estos cincuenta años de evolución política, cultural y académica. Jim Clifford describe su ensayo sobre los 25 años después de Writing Culture como "pintar con una escoba» (2012:423); mi recopilación aquí podría compararse mejor con el rastreo de escogidas piezas de la pintura con un palillo de dientes. Partes de este texto fueron originalmente presentadas en la conferencia internacional «Beyond Modernity: Do Ethnography Museums Need Ethnography?», en el Museo Nazionale Preistorico Etnografico L. Pigorini, Roma, del 18 al 20 de abril de 2012.
} 
En contra del background de esos acontecimientos, los antropólogos experimentaron un creciente malestar con las prácticas tradicionales de su disciplina. El trabajo de campo, en otro tiempo «el estudio de 'otros' de piel oscura por blancos Euro-Americanos dirigido a la recuperación de la alteridad pura, sin contaminar» (Stocking, 1992:358), comenzaba a vislumbrarse de forma gradual de manera inviable bajo esa condición, en tanto que sus principales objetos asumían nuevas identidades poscoloniales. Los antropólogos (al menos gran parte de ellos) comenzaban percibir que la imagen científica y objetiva de sus investigaciones necesitaba ser seriamente repensada de cara a que las nuevas perspectivas fueran tomadas en consideración. Uno de los múltiples factores desencadenantes fue el reclutamiento de antropólogos por parte de la Agencia Central de Inteligencia (CIA) (en ocasiones real, en otras imaginario), que tuvo un punto crítico entre 1964 y 1965 con la revelación del «Proyecto Camelot» (poniendo un nuevo rostro al viejo malestar sobre los lazos entre antropología y colonialismo) y que promovió un reforzado sentido del compromiso con aquellos cuyas vidas estaban siendo estudiadas ${ }^{4}$.

Al mismo tiempo, parte de la energía intelectual que había sido dirigida al campo de los estudios antropológicos y sus conclusiones fue desplazada hacia el emergente campo de los «Cultural Studies» (los «Estudios Culturales»). Originada en el Reino Unido, esta nueva y notoriamente interdisciplinar amalgama compartía el interés de la antropología por los asuntos sociales y culturales, pero los ubicó en un nuevo entorno, alejado del estudio de "otros de piel oscura por blancos Euro-Americanos», al atraer expertos de una amplia variedad de orígenes étnicos y nacionales, centrado en relaciones globales de poder, teoría literaria, estudios cinematográficos, estudios étnicos, cultura popular, economía política y mucho más 5 .

A principios de la década de los 70, las propuestas por la «reinvención» de la antropología (Hymes, 1969) resultaron en visiones que ofrecían protagonismo de la agencialidad de aquellos cuyas vidas estaban siendo exploradas, y algunas de las anteriormente incuestionables aproximaciones en la investigación antropológica estaban siendo escudriñadas en su compatibilidad con el recién configurado campo. Tomemos, por ejemplo, la antigua práctica de tomar notas

${ }^{4}$ Medio siglo después, los debates sobre el uso militar de los «Equipos Humanos sobre el Terreno» en Iraq y Afganistán situaron las mismas cuestiones en el debate. Véase GonZÁLEZ, 2008.

5 Los «Estudios Culturales» se originan con esa denominación en 1964, en Gran Bretaña. En los Estados Unidos, el primer programa de doctorado en Estudios Culturales fue inaugurado en 1994 (en la Universidad George Mason). 
de campo, grabaciones y fotografías de forma clandestina —algo habitual en la caja de herramientas del etnógrafo durante la década de los 60-. Por ejemplo, el buque insignia de las revistas de la disciplina, American Anthropologist, publicó una técnica de trabajo bastante compleja para documentar ceremonias de larga duración sin revelar a los nativos que sus actividades estaban siendo grabadas, y constituyó todavía una lectura recomendada para los estudiantes de grado a la hora de emprender un trabajo de campo en los sesenta (Sturtevant, 1959). Pero como las sensibilidades hacia las personas que estaban siendo estudiadas fueron desplazadas al centro de la escena, ese tipo de documentación "científica» clandestina fue proyectada bajo un nuevo y negativo foco en tanto que las personas que previamente habían sido representadas como «informantes» de manera rutinaria, llegaron a ser reconocidos por la gente que investigaba sus vidas como individuos con derecho a la transparencia.

La clave para todo ello se encuentra en el momento en el que los grupos estudiados dejaron de ser vistos como grupos culturales aislados, en tanto que los antropólogos comenzaron a situar las sociedades y las culturas que estudiaban en contextos más amplios de lo que habían hecho sus predecesores de mediados del siglo XX. La crítica de Eric Wolf en 1982 de una visión en la cual las naciones, sociedades o culturas eran representadas como homogéneos y acotados objetos, girando unos contra otros como duras y redondas bolas de billar (1982:6-7), delimitó el nuevo escenario. A diferencia de los anteriores intentos por discernir los rasgos culturales que distinguirían los estilos de vida de un pueblo de los de otro, los antropólogos comenzaron a dirigir su mirada de manera más frecuente tras los portales donde las ideas sociales y culturales se abrían paso a empujones en su desplazamiento de un contexto social y cultural a otro. Y mientras el énfasis en la investigación etnográfica había estado en su día en la abstracción por el pasado desde un revestimiento de modernidad para descubrir tradiciones culturales no contaminadas $^{6}$, la modernización llegó a ser vista como un elemento central de la empresa, proporcionando un trampolín para la exploración de la creatividad cultural y la auto-afirmación.

Una consecuencia de esta reorientación general fue el rechazo categórico hacia la forma y el contenido tradicional de las monografías etnográficas, lo que dio paso a una variedad de textos experimentales. Por ejemplo, el de Paul

${ }^{6}$ Piénsese en Franz Boas sosteniendo una manta para tapar las modernas casas de dos plantas tras los nativos Kwakiutl que estaba filmando para los archivos etnográficos, como queda reflejado en la serie de videos Odyssey, dedicada a este padre de la antropología norteamericana. 
Rabinow en Marruecos (1977) humanizó la experiencia del trabajo de campo a través de reflexiones sobre las relaciones entre el antropólogo y aquellos cuya cultura estaba siendo estudiada; el trabajo de Renato Rosaldo entre los Ilongot (1980) mostró la relevancia de la historia para una clase de grupos una vez imaginados como "primitivos intemporales»; el de Richard Price entre los Saamaka (1983) jugó con el diseño de página y diferentes tipos de letra para enfatizar la perspectividad en la historia oral, los archivos coloniales y en la etnografía; y el trabajo de Michael Taussig en Colombia mezcló géneros para subrayar el reconocimiento de que los hechos no pueden existir fuera de su interpretación ni la verdad fuera de su representación. Libros como éstos desmantelaban y complicaban activamente la autoridad etnográfica, rechazando el atemporal concepto antropológico conocido como "presente etnográfico" a favor de una cuidadosa atención al cambio a través del tiempo. Esos cambios presagiaban la muerte de la monografía etnográfica tradicional y sus reclamos como verdad incontestable. El apoyo al nuevo rumbo —el más importante de la mano de Writing Culture de James Clifford y George Marcus en 1986 y el trabajo de James Clifford, The Predicament of Culture, en 1988 - aseguraba que no había vuelta atrás. Tal y como un comentarista expresó, Writing Culture introdujo un nuevo «escepticismo sobre las explicaciones ordenadas y las construcciones de modelos teóricos en favor de una visión de cultura y sociedad más movible, indefinida, como un terreno de hibridación, disyunción y heteroglosia (Starn 2012: 412). Hablar de ciencia objetiva ya no estaba de moda y en su lugar se hablaba de poéticas y políticas, de fragmentos y verdades parciales, de subalternidades y se discutía sobre reflexividad y posiciones de los sujetos.

Los museos no fueron - todavía - participantes activos en la recién configurada visión de la antropología, pero el estruendo del cambio en el mundo del arte estaba sentando las bases para una relación más colaborativa (y a veces confrontacional) entre las aproximaciones críticas del arte y la antropología respecto a la exhibición de objetos más allá de la órbita Euroamericana. La primera mitad de la década de los ochenta constituyó un momento de explosivo interés por las representaciones públicas de lo que podríamos denominar «arte etnográfico». Algunos ejemplos en la ciudad de Nueva York pueden servir para ilustrar la tendencia. El Metropolitan abrió el ala Rockefeller, dedicada al arte de África, Oceanía y las Américas, en 1982; El Museo de Arte Africano abrió sus puertas en 1984; y durante 1984 y 1985, Nueva York acogió la presentación de numerosas exhibiciones de gran éxito centradas en arte no occidental. "Primitivismo en el arte del siglo XX. Afinidades entre lo Tribal y lo Moderno» fue inaugurado en el Museo de Arte Moderno con una asistencia de seis mil personas; en relación a 
esa exhibición, una lista impresionante de antropólogos e historiadores del arte participaron en un animado seminario de dos días en el museo que pretendía abrir un nuevo diálogo interdisciplinar sobre las relaciones entre arte occidental y no occidental 7 . La exhibición "Te Maori» en el Metropolitan Museum of Art fue inaugurada con un ritual en el que sesenta dignatarios maoríes repletos de insignias participaron en cantos, canciones, bailes y gritos de guerra y saludaron al alcalde de Nueva York con el roce de sus narices. Para la exhibición «Asante: el Reino del Oro", en el Museo Americano de Historia Natural, el rey Asantahene, Otumfuo Opoku Ware II, llegó de Ghana para participar en las ceremonias de apertura, y marchó a través de Central Park junto al alcalde de la ciudad bajo un enorme paraguas de seda, siendo acompañados por una procesión de varios miles de participantes. La Galería de Ciencia y Arte IBM exhibió la mayor colección de arte indígena de la costa noroeste nunca vista hasta entonces. El Instituto AfroAmericano ofreció una exposición denominada «Beauty by Design: La estética del Adorno». La lista podría seguir y seguir.

Al mismo tiempo que los antropólogos se movían más allá de su asentada tradición por las sociedades de pequeña escala, «tribales» o "primitivas», los historiadores del arte se mostraban menos reacios a aceptar materiales ajenos a las áreas usuales de su disciplina, haciéndolo con un cada vez más sofisticado dominio de conceptos antropológicos, como se puede atestiguar en publicaciones del Museo de Historia Cultural de la UCLA (más tarde el Museo Fowler) o importantes estudios de arte africano de investigadores como Henry y Margaret Drewal. El trabajo del crítico del arte Lucy Lippard resultó particularmente importante en la apertura de la crítica del arte en llamar la atención sobre el alcance y la vitalidad de la escena del arte multicultural en el país; por ejemplo, su libro de 1990 - Mixed Blessings: New Art in a Multicultural America - proporcionaba un auténtico "quién es quién» de artistas de toda gama. Como resultado de la ampliación del campo, el conjunto factores — sociales, culturales, económicos, políticos- que daban estructura, textura y significado (argumentado o no) a la cuestión más tradicional de los objetos artísticos y su historia colectiva comenzó a tener una mayor importancia. Al mismo tiempo, aumentó el interés por el examen de la ética museística, las estrategias de comisariado, las políticas de subastas, las dinámicas del mercado y los objetivos de los coleccionistas. Incluso fue ampliamente reconocida la delicada posibilidad de que el etnocentrismo ace-

7 La exhibición, comisariada por historiadores del arte occidental con reducido conocimiento etnográfico y poca sensibilidad antropológica, inspiró un aluvión de reacciones críticas que ayudaron a la configuración de las aproximaciones al arte etnográfico durante las décadas siguientes. 
chaba en el centro mismo de los postulados de los expertos. Al situar de manera enérgica los objetos artísticos, las biografías de los artistas y la evolución de las secuencias estilísticas en el contexto de percepciones condicionadas por factores sociales y culturales, los acercaron a las tradicionales preocupaciones e intereses de la antropología, y comenzó a erosionar la persistente tentación (más fuerte en unos críticos que otros) de contemplar la historia del arte como el estudio prístino y apolítico de las formas estéticas.

En 1985, en reconocimiento a esta tendencia, la Universidad Johns Hopkins estableció un innovador programa de doctorado, financiado generosamente por la Fundación Nacional para las Humanidades (Nacional Endowment for the Humanities, NEH), con el propósito de formar estudiantes en la intersección entre la antropología y la historia del $\operatorname{arte}^{8}$. Y ese mismo año, el encuentro en la reunión anual de los historiadores del arte (la College Art Association) albergó, por primera vez en su historia, paneles de lo que se llamó «arte etnográfico» —un movimiento considerado tan revolucionario que los participantes en aquellos paneles, incluida yo misma, fuimos trasladados a la Fundación Getty en California, para un debate de varios días de duración sobre la mejor forma de hacer nuestra entrada trascendental—?

Al mismo tiempo que el arte etnográfico comenzaba a ser aceptado como un campo de interés legítimo de la historia del arte, el diálogo entre antropólogos e historiadores del arte se acrecentaba y los estudios de arte turístico, copias, falsificaciones, apropiaciones y formas derivadas de los originales comenzaron a atraer una atención creciente. Unpacking Culture, fruto de la colaboración entre el historiador del arte Ruth Phillips y el antropólogo Christopher Steiner, desarrollaba un asunto que, en mi opinión, debe tener implicaciones especialmente importantes para los museos, en el sentido que fuerza el reconocimiento del influyente rol de los coleccionistas y los tratantes de arte en las elecciones que toman los museos que exhiben arte etnográfico. Abogando por la importancia de revisar la clásica visión en la que los objetos podrían ser categorizados como «arte» o como «etnografía» escribían:

${ }^{8}$ Fui nombrada directora del programa, pero debido a razones demasiado complejas y personales para desarrollarlas aquí, renuncié en la universidad después del primer año. El programa, con un apoyo insuficiente por parte de los dos departamentos, fue desmantelado unos ańos más tarde.

9 Mi presentación en este encuentro de la CAA, titulada "Primitive Art in Civilized Places», fue ampliada en un libro con el mismo nombre en 1989 (publicado en espańol en 1993). 
Durante más o menos un siglo, los objetos de los «Otros» culturales han sido incluídos dentro de dos... categorías: el artefacto etnográfico y la obra de arte (encuadrándolos dentro de) los dominios eruditos definidos a finales del siglo XIX, momento en el que la antropología y la historia del arte se establecieron formalmente como disciplinas académicas. En tanto que construcción, sin embargo, esta división binaria ha sido casi siempre inestable porque ambas clasificaciones enmascararon lo que, a finales del siglo XIX, era ya una de las más importantes características de los objetos: su funcionamiento como mercancías en circulación en el discursivo espacio de una emergente economía capitalista (1999: 3).

En el mundo del museo, el creciente interés de los historiadores del arte por el arte no Occidental trajo inevitablemente consigo sugerencias sobre una (tentativa, parcial y ambivalente) apertura a la idea de incluir la participación directa de miembros de las culturas representadas en las exhibiciones de arte etnográfico. Mientras que los grandes museos de la década de los ochenta habían empezado a abrir de buena gana sus puertas a los objetos artísticos de otras culturas, se mostraban aún renuentes a la idea de dar la bienvenida a los discursos y las sensibilidades estéticas de las personas que los habían creado. Esto es, a pesar de que esos objetos artísticos estaban siendo exhibidos en las vitrinas de los museos o ilustrados en catálogos, las decisiones acerca de cómo exponerlos y los textos que los autentificaban e interpretaban estaban aún en manos de comisarios EuroAmericanos - una práctica que, como el crítico cubano Gerardo Mosquera ha señalado, favorecía fuertemente los «valores universales» basados en un "criterio Eurocéntrico o aún Manhattan-céntrico» (1994:134)—. Sin embargo, en la década de los noventa algunas grietas comenzaron a aparecer en el muro que separaba los representantes de los representados. El cambio fue evidente primero en las exhibiciones temporales: en 1991, por ejemplo, el Museo Americano de Historia Natural puso especial cuidado en la realización de su exhibición de Arte Indígena de la Costa Noroeste («Chiefly Feasts: The Enduring Kwakiutl Potlatch») a través de una acción colaborativa entre comisarios de la ciudad de Nueva York y miembros de las sociedades de la Costa Noroeste (Jonaitis, 1991). Pero como esto se desplazaba hacia áreas más generales, como museos de variada tipología (el Smithsonian en Washington, el Museo Americano de Historia Natural en Nueva York, el museo Haffenreffer de la Universidad Brown entre otros) se convocarían comités consultivos con el fin de integrar la participación de los representantes nativos en la toma de decisiones sobre las galerías de sus exhibiciones y las cuestiones que tienen impacto en su funcionamiento general (ver, por ejemplo, Arnoldi, 2005; Krech, 1994). La evidencia más notoria de este movimiento por 
las voces nativas, por supuesto, fue la creación del Museo Nacional del Indígena Americano en 2004, que es dirigido por miembros de las culturas indígenas americanas. De hecho, la tendencia creciente hacia la «antropología colaborativa» ha tenido una gran influencia en la manera en que los museos están manejando sus colecciones; por poner un ejemplo, véase el proyecto «10,000 Kwentos», en el que la comunidad filipina está colaborando con el Field Museum de Chicago para documentar los objetos almacenados ${ }^{10}$.

La acogida por parte de los museos de materiales que cuestionaban las jerarquías tradicionales no se produjo sin una virulenta oposición, y las acaloradas disputas sobre los intentos por promover los esfuerzos multiculturales o aquellos que desafiaban el canon en los Estados Unidos llegaron a ser una parte prominente de lo que fue conocido como las "Guerras Culturales». En el mundo académico, Harold Bloom, un distinguido profesor de Humanidades en la Universidad de Yale, arremetió contra la nueva disposición de la literatura que se hacía eco de las agendas feministas, marxistas o multiculturales, demandando la vuelta del canon occidental tradicional enfocado en autores como Chaucer, Shakespeare, Freud o Beckett. En el contexto político, grupos conservadores como la Coalición Cristiana peleaban contra el uso de los impuestos para apoyar las artes, abogando por la eliminación de la Fundación Nacional para las Artes (NEA) y la Fundación Nacional para las Humanidades (NEH). Y fueron reforzados por la circunstancia que Lynn Cheney (esposa de Dick Cheney, más tarde vicepresidente del país con George Bush hijo) dirigía la Fundación Nacional para las Humanidades (1986-1993), con un fuerte apoyo primero del presidente Ronald Reagan y después del presidente George Bush padre. Durante estos periodos, el apoyo gubernamental a las exhibiciones de los museos sufrió un severo revés, con consecuencias especialmente draconianas para todo aquello que traspasara la línea marcada por el canon cristiano, heterosexual y étnicamente Euro-Americano ${ }^{11}$. Dentro de la gran batalla, las sexualidades alternativas llegaron a ser el objetivo más mediatizado, seguido muy de cerca por las diferencias raciales, étnicas y religiosas ${ }^{12}$. La financiación gubernamental estaba en el centro de la cuestión, «ya

10 Ver http://10000kwentos.org/ (visitada el 2 de marzo de 1914).

11 Para un detallado informe sobre la tormenta política en torno al apoyo gubernamental a las artes y las humanidades, ver Косн 1998. Para una recopilación relativamente exhaustiva de las declaraciones de políticos, periodistas y artistas entre otros, véase Bolton, 1992.

${ }_{12}$ Una exposición de fotografías de Robert Mapplethorpe, que incluía representaciones de hombres de color en poses homo-eróticas, fue un pararrayos especialmente destacado. Las acusaciones de pornografía y los intentos de censura se enfrentaron a los defensores de la libertad artística en una batalla que fue noticia de portada, en tanto que la Corcoran Gallery de Washing- 
que tanto que predicadores como políticos censuraron cierto tipo de arte como inmoral, blasfemo o antipatriótico [y] pretendieron reducir o eliminar los fondos para el arte en general» (Yenawine, 1999:9). Activistas de izquierdas, trabajando con poco más que la fuerza de sus convicciones, contraatacaron, congregando a grupos sin ánimo de lucro que promovían la idea de un arte con conciencia social; por ejemplo, el colectivo "Art Matters» ofreció becas de investigación a artistas cuyo trabajo se había puesto en peligro a causa de los escalofriantes efectos de las guerras culturales y aportaron financiación inicial a un buen número de organizados esfuerzos que desafiaron de manera directa la posición del gobierno sobre la financiación cultural y el SIDA ${ }^{13}$.

A pesar de todo su poder, políticos como Cheney fueron incapaces de dar al traste con el incesante entusiasmo de numerosos académicos, críticos o empleados de museos entre otros, de una orientación no conservadora, en cuestionar y luego rechazar las jerarquías elitistas, la visión las sociedades como aislados culturales estáticos y la idea de que los contactos ponían en peligro la «autenticidad» cultural y, al contrario, dirigir su atención hacia un contexto global fluido, en el que las ideas y las prácticas se desplazaban de un contexto cultural a otro. Incluso el vocabulario corriente reflejó esas tendencias, y las metáforas del viaje, de los terrenos fronterizos o las zonas de contacto estaban por todos lados. La representación del artista chicano Guillermo Gómez-Peña capturó el sabor de este marcadamente itinerante mundo del arte cuando escribía: «Escribo en aviones, en trenes y cafeterías. Viajo de una ciudad a otra, de costa a costa, de país en país, contrabandeando mi trabajo y el trabajo y las ideas de mis colegas... El hogar es a la vez 'aquí' y 'allî o algún lugar entre medias. A veces no está en ningún sitio... Aquí/allí, estar

ton cancelaba la exposición y se sometía a debate el derecho del Museo de Arte de Cincinnati a exhibir las fotografías de Mapplethorpe en un juicio enormemente mediatizado por obscenidad. El clamor contra el «Piss Christ» (Andrés Serrano) encendió la mecha para otra acalorada confrontación entre los puntos de vista conservadores y liberales, esta vez centrado en la religión más que en la sexualidad; una de mis estudiantes en los Estados unidos, cristiana devota, se negó a leer un artículo sobre la censura en las artes que yo había asignado debido a que mencionaba esa obra de arte —una señal de cuán profundos sentimientos se ponen en juego en esta clase de asuntos-.

13 A pesar de la buena organización de los colectivos de activistas por el arte, que empujaron su agenda con pasión y determinación, los obstáculos fueron desalentadores y los sentimientos de profunda frustración —incluso en los más fervientes luchadores resultaron inevitables (véase LIPPARD 1999). "Art Matters» — «El arte importa»— (creado a principios de la década de los 80) se quedó sin fondos en 1996, aunque fue reiniciado en 2007 y ha estado apoyando de nuevo a una amplia variedad de artistas que están empujando los límites estéticos y sociales, en esta ocasión con una especial atención en la comunicación y la colaboración entre las fronteras nacionales (Yenawine 1999). 
sin hogar, la cultura fronteriza y la desterritorialización constituyen la experiencia dominante» (2001:5-6). Los títulos de libros reflejan esta tendencia: The Traffic in Culture (Marcus \& Myers, 1995), Routes (Clifford, 1997), Destination Culture (Kirshenblatt-Gimblett 1998), y Unpacking Culture (Phillips \& Steiner 1999), por nombrar simplemente algunos. Dentro del mismo espíritu, James Clifford rechazó de manera sólida la idea de que la cultura se centraba en lugares circunscritos, argumentando que el «desplazamiento» debía ser visto como «constitutivo de significados culturales» (Clifford, 1991, 1997:3). Refiriéndose a los escritos de Amitav Ghosh, evocó las salas de tránsito de los aeropuertos (u otros espacios de cruces culturales transitorios, como los vestíbulos de los hoteles, las estaciones de trenes o los hospitales) como un sustituto para las aldeas que habían proporcionado el campo tradicional de la antropología en una era anterior ${ }^{14}$. Una de las consecuencias de esta nueva visión fue que tanto el arte turístico como el de aeropuerto se desprendió de su reputación de trivialidad o falta de autenticidad, convirtiéndose en un asunto de importancia para investigadores y siendo elevado en respetables campos de estudio tanto en la antropología como la historia del arte.

Dos monumentales seminarios, dirigidos por Ivan Karp y sus colegas en 1988 y 1990 en la Smithsonian Institution, exploraron cada rincón y cada grieta del recién conceptualizado campo en todo lo que atañía al mundo museístico ${ }^{15}$. $\mathrm{Al}$ mismo tiempo, un par de seminarios de amplio espectro, organizados por la Asociación de Directores de Museos de Arte en 1990 y 1991, reunieron a una impresionante lista de críticos con el fin de encontrar vías de lidiar con una situación en la que, como los organizadores señalaron, las personas de color más visibles en la mayor parte de los museos de arte eran o bien los vigilantes de seguridad o bien el personal del Departamento de Educación que trabajaba en el sótano con los escolares de los barrios marginales (Tucker, 1992:9-10).

${ }^{14}$ Mientras Stocking es generalmente considerado como el más destacado historiador de la Antropología, Clifford es su crítico igualmente preeminente. Gran parte del carácter persuasivo de su argumento en favor de una visión del campo fragmentaria y descentralizada descansa en un estilo de escritura que se ha caracterizado por el uso de «imágenes instantáneas» — «snapshots»—. Él «inclina el balance» de la dialéctica, «forcejea, nunca exitosamente tranquilo» para liberar términos de sus antiguas connotaciones, sazonando su prosa con "vacilaciones», "preguntas, no conclusiones», "aproximaciones cautelosas», "vagando», "preguntado si», "escudriñando»y "preocupándose por» las ideas, para al final "problematizar» o «complicar» las interpretaciones, evitando cuidadosamente pretender llegar a verdades finales.

15 Tales seminarios fueron publicados como Exhibiting Cultures, en 1991 y Museums and Communities en 1992, y un tercero bajo el impulso del momento, en 2006, bajo el título de Museum Frictions (Véase Karp et al. 1991, 1992, 2006). 
La preocupación por el respeto a los derechos de las naciones soberanas en lo concerniente a la propiedad cultural había animado enérgicos debates sobre el muy delicado asunto de la repatriación durante décadas, con el resultado de diversos acuerdos internacionales. La Convención de UNESCO de 1970 - Medios de Prohibición y Prevención de la Importación, Exportación y el Comercio Ilícito de la Propiedad Cultural - fue el primer tratado internacional sobre el tráfico de la propiedad cultural. Un Código Ético para Museos fue adoptado por el Consejo Internacional de Museos (ICOM) en 1986 (revisado en 2004). Y en 1995, el Instituto Internacional para la Unificación del Derecho Privado (UNIDROIT) se reunió en Roma para preparar su convención sobre los objetos culturales robados o ilegalmente exportados. En los Estados Unidos, la aprobación de la Ley de Protección y Repatriación de las Tumbas de los Nativos Americanos (NAGPRA), en 1990, fue un respaldo clave para la agencialidad de los pueblos nativos, pero hubo también incontables movimientos de menor tamaño en la misma dirección. El respeto a las objeciones nativas a la exhibición de una Kachina Zuñi en una muestra sobre «Primitivismo» del MOMA, en 1984, fue uno de los numerosos indicios de esta tendencia ${ }^{16}$.

Aunque el giro hacia una nueva visión de la relación entre los observadores occidentales y las personas cuyas vidas estaban estudiando estaba tomando fuerza en la comunidad antropológica, cabe señalar que los miembros de la disciplina se encontraban lejos de la unanimidad en este asunto. Reconociendo el aparentemente inevitable fallecimiento de la antropología tradicional dentro de un «mundo descentralizado, fragmentado, comprimido, flexible, refractivo y posmoderno», algunos antropólogos reaccionaron lanzando de manera vehemente proclamas anti-posmodernistas para «reconquistar la autoridad etnográfica y salvarla así de lo que ellos veían como el «difuso populismo y el esnobismo invertido» de los posmodernistas (Fox 1991) para con los desfavorecidos. Un punto de inflexión se produjo cuando los antropólogos Barbara y Dennis Tedlock —una antigua artista y un traductor de poesía Maya, respectivamente- se convirtieron en editores del buque insignia de la disciplina, la revista American Anthropologist. Su editorial de

16 Para un meditado texto sobre las complejidades (y las ironías) en los intentos de devolver los objetos de los museos a sus propietarios originales, véase AppiaH 2006. Los ensayos contenidos en la obra de Brown (2003) exploran casos en torno a los derechos de propiedad material e inmaterial en los Estados Unidos y otras partes del mundo, mostrando las espinosas compensaciones y arreglos que envuelve la legislación de la propiedad cultural. 
apertura lanzó un llamado por las «nuevas formas de trabajo de campo y los nuevos modos de representación», situando de frente el debate dentro de la antropología:

En el trabajo de nuestros compañeros más jóvenes, en particular, vemos más señales de lo obsoleto de la arquitectura tradicional de la disciplina. Esperamos que tengan el valor de hacer caso omiso a los que dicen que lo que hacen no es "auténtico», con referencia a un tema u otro, y proseguir con la labor de remodelar nuestra disciplina... Algunos incluso pueden intentar pronosticar si los antropólogos dejarán su afán de mantener las barreras, insultar y propagar rumores a tiempo de seguir con su trabajo o si seguirán con sus prácticas sociales destructivas hasta que se colapse la disciplina en sus ínfimos subcampos enfrentados. Otros pueden imaginar una dirección totalmente nueva para nuestra excepcional disciplina en los cambios demográficos globales a los que nos enfrentaremos tanto nosotros como nuestros alumnos en nuestra investigación, en nuestros textos y en nuestras vidas mismas. ¿Cuáles serán nuestros futuros humanos y antropológicos? (1995).

El formato revista se alargó para permitir la inclusión de materiales visuales, y el contenido se desplazaba de manera perceptible hacia ensayos con un mayor contenido de arte y literatura, con el consiguiente descenso de la "ciencia dura». Todo esto causó escándalo entre los antropólogos que trabajaban a la manera "científica» más tradicional, desde análisis componenciales hasta la etnociencia, que casi llegan a las manos con los "posmodernistas» durante una encendida confrontación en el encuentro plenario de la Asociación Americana de Antropología (AAA) de 1995.

Mientras tanto, la atención empática al ascenso del multiculturalismo en el país era palpable en el resto de la sociedad y los medios de comunicación estuvieron rápidos en la respuesta. Entre 1990 y 1993, la Radio Pública Nacional (NPR), en cooperación con el Museo Mexicano de San Francisco, apoyó de manera generosa una serie de encuentros de un grupo que fue conocido como "Grupo de Trabajo en una Nueva Sensibilidad Americana», encaminados a ensanchar la programación de la radio a fin de que incluyera voces de cada segmento de la creciente población multicultural del país. Miembros prominentes de toda variedad de afroamericanos, nativos americanos, asiático-americanos, americano-caribeños y las comunidades de chicanos, acompañados de una muestra de minoría blanca, se reunieron para desarrollar ideas acerca de los modos de integrar a sus compañeros de manera más completa en los medios americanos 
—la radio y demás — ${ }^{17}$. Al mismo tiempo, el formato de los noticieros se alejó del modelo monocorde de presentadores (personificado hasta 1980 por Walter Cronkite) y comenzaron a relatar de manera más frecuente acontecimientos a través de un mosaico de voces étnica, cultural y regionalmente diversas.

\section{¿Así que dónde están las cosas hoy en día?}

Esos acontecimientos, entrelazados con las políticas nacionales, culturales y académicas (sean vistas como "poscoloniales», "posmodernas», «contra-hegemónicas», «reflexivas» o cualquier otra caracterización) han alimentado diálogos en cada uno de los aspectos de la vida en los Estados Unidos, desde (por ejemplo) las admisiones universitarias, los programas de asistencia social, las leyes de inmigración o los derechos de los homosexuales hasta los tres dominios (arte, antropología y museos) que han centrado la atención de este texto. En un contexto académico, esto ha significado la desaparición (o al menos el parcial abandono) de la tendencia anterior en entender la historia del arte (y la crítica artística) como el estudio prístino y apolítico de las formas estéticas, y la antropología, igualmente, como el estudio prístino y apolítico de los grupos culturales aislados. Pero los acontecimientos en cuestión han arraigado completamente lejos de los salones de la academia en los que esas disciplinas eran modeladas y han pasado a una nueva generación. Podemos generalizar sin temor que lo acontecido tanto en los Estados Unidos como en la arena global ha significado que el privilegio una vez ostentado por Euro-Americanos de hablar en representación de culturas lejanas se ha diluido. Como resultado, el mundo museístico ha experimentado una quiebra en la división que Gerardo Mosquera señaló entre "culturas comisariadas» y «culturas comisarias» (1994:135). En Antropología, la otrora nítida separación entre la población de «los etnógrafos» y la de «los etnografiados» (Marcel Maget, citado en Sherman 2011:24) no será nunca más capaz de sostenerse de forma tan clara como una vez lo fue. Y de manera más general podemos hablar de cómo se desdibuja la distinción de lo que el novelista Toni Morrison ironizaba como «los definidores y los definidos» (1987:190).

${ }^{17}$ Esta iniciativa fue organizada por Peter Pennekamp (Vicepresidente para la Programación Cultural de NPR) y Virginia Fields (Los Angeles County Museum of Art). Entre los participantes se encontraban: Marie Acosta-Colon, Henry Louis Gates Jr., Suzan Harjo, Steven Lavine, Lawrence Levine, Mari Matsuda, Raymund Paredes, Richard Price, Sally Price, Bernice Johnson Reagon, Jack (John Kuo Wei) Tchen, Trinh Minh-ha, Marta Vega, Jim West, y Tomás YbarraFrausto. 
La aceptación de nuevas voces ha sido particularmente incisiva en los cambios en la cultura pública, la historia del arte, la antropología y los museos, en tanto que las personas cuyas vidas son representadas por éstos - ya sea en libros o en el interior de edificios - han comenzado a hablar por ellos mismos cada vez con más frecuencia. Individuos que antes caían anónimos dentro de las representaciones genéricas de sus respectivas culturas son hoy llamados por su nombre ${ }^{18}$. Los viajes a escala global, las oportunidades educativas, las políticas identitarias, los patrones de inmigración y las nuevas tecnologías de comunicación han creado un mundo en el que las personas cuyas vidas están caracterizadas en las exhibiciones de museos etnográficos están cada vez mejor posicionadas para explicar su historia, sus prácticas culturales o sus tradiciones en su propia manera, sin tener que pasar siempre a través de la intervención de interlocutores occidentales. En la mayoría de los museos de los Estados Unidos, participan ahora en la toma de decisiones de toda clase y condición, desde los modos de exhibición y el fundamento de las interpretaciones hasta las políticas de adquisición y los debates sobre repatriaciones.

Nada de esto quiere decir que, en la relación entre arte, antropología y la diferencia cultural en los Estados Unidos, el vaso esté más que medio lleno ${ }^{19}$. Desde 2009, las políticas del «Tea Party» han envalentonado y empoderado a un creciente número de conservadores fundamentalistas (a menudo evangélicos), con el resultado de que aquellos que no comparten su visión del mundo — desde la educación y la sexualidad a los servicios sanitarios, el control de las armas o el medio ambiente- tienen que vérselas con adversarios temibles e intransigentes. (No necesitamos irnos tan lejos como el mundo árabe para comprender las potenciales consecuencias destructivas para la cultura de una coalición entre fervor religioso y poder político). De manera inevitable y en momentos imprevisibles, ese tipo de inclinaciones en la política nacional proyectan su sombra en el mundo del arte y los museos, introduciendo en el interior del debate público un manojo de argumentos religiosos, legales y en la crítica artística ${ }^{20}$.

18 Tal y como un crítico apuntó en 1994, «Lo Anónimo tiene Nombre» (Walker 1994).

19 Tal y como Ruth Phillips asegura: «identificarse como un historiador del arte del "arte tribal” es, incluso hoy en día, considerado como un oxímoron para muchos historiadores del arte de la corriente dominante» (2011: 107).

20 En 1999, el alcalde de Nueva York intentó cerrar el Museo de Arte de Brooklyn al entender como una blasfemia para su fe católica una de las piezas de artes allí exhibida. Véase Rothfield 2001 para una excelente recopilación de reflexiones en este altamente mediatizado caso. 
Aunque este trabajo se ha centrado exclusivamente en los Estados Unidos, vale la pena señalar que otras partes del mundo han estado experimentando muchos de los mismos debates acerca del manejo de la diferencia cultural en los museos. Termino este ensayo con unas breves anotaciones con algunos de los entornos museísticos sobre los que al menos he tenido un pasajero contacto, con la intención de ofrecer cierto sentido de variedad de las formas que éstos pueden tomar ${ }^{21}$.

Canadá ha sido incluso más pro-activo que los Estados Unidos en el asunto de dar voz a las poblaciones nativas ${ }^{22}$. Impulsados en parte por el informe de un grupo de trabajo en 1992, «Pasar página — forzando una nueva alianza entre los museos y los Pueblos Originarios»— la investigación colaborativa con conservadores indígenas (algunos de ellos integrados en el «Colectivo Conservador Aborigen») ha ido en aumento. Un número creciente de exposiciones abordan la vida aborigen contemporánea (incluyendo la vida urbana). Así mismo, la Asociación de Arte Nativo Americano (fundada en 1981) refleja el creciente énfasis en el diálogo interdisciplinar entre la historia del arte, los estudios museológicos, los estudios indígenas y la antropología.

En Brasil, el Instituto Brasileño de Museos (IBRAM), creado bajo el mandato de Gilberto Gil como ministro de Cultura, ha trabajado en la revitalización de grupos sociales populares interesados en preservar su propia cultura, ofreciendo apoyo gubernamental a una red de Pontos de Cultura —organizaciones de base que incluyen desde grupos de carnaval o museos localizados en favelas hasta diversos colectivos locales. Los grandes museos han estado experimentando con la conservación intercultural. El Museo de Arqueología y Etnología de São Paulo invitó a Indígenas Kayapo (elegidos en su comunidad) para colaborar en la documentación de su colección, lo que condujo a nuevas e interesantes perspectivas sobre la apertura de un contexto cultural a los cambios a lo largo del tiempo (Gordon \& Silva 2005).

${ }^{21} \mathrm{Mi}$ agradecimiento a los colegas que me proporcionaron ayuda con los párrafos finales de este texto: Ivan Bargna, Olivia Gomes da Cunha, Marc-Olivier Gonseth, Guido Gryseels, Lotten Gustafsson Reinius, Clare Harris, Paola Ivanov, Maria Camilla de Palma, Giovanna da Passano, y Solen Roth. Véase también la reciente descripción general de los museos etnográficos europeos llevada a cabo por Clare Harris y Michael O'Hanlon (2013).

${ }^{22}$ Para una discusión de la situación en Canadá desarrollada por dos participantes clave, véase Ames 1992 y PhiLlips 2011. 
En Holanda, el Tropenmuseum de Amsterdam ha sido objeto de una reorientación fundamental, iniciada en la década de 1960, en parte como respuesta a una iniciativa del Ministerio del Exterior para fomentar la conciencia social en problemas como la pobreza y la discriminación. Un instrumento fundamental para este giro activista fue la creación de «entornos vivos» para lo que se llamó «el Sur» (África, Sudamérica, el sudeste Asiático, etc.). Las exposiciones han abordado la falta de hogar, la distribución de las reservas de agua, la posición de la mujer, la salud, el desarrollo, la irrupción de nuevas culturas urbanas y diversas dimensiones de la cultura popular, todo lo cual ha desplazado muy lejos la identidad de la institución como museo colonial en sus orígenes a finales del siglo XIX.

En Suecia, el Museo de Etnografía de Estocolmo ha organizado exhibiciones centradas en asuntos como la participación escandinava en el Estado Libre del Congo, la presencia de restos humanos en las colecciones suecas o los actuales debates sobre la repatriación.

En Bélgica, el otro tiempo aburrido anticuado Museo Real de África Central, en Tervuren, se encuentra en un intenso proceso de redefinición desde el clásico museo colonial a un modelo de sensibilidades poscoloniales, incluyendo una crítica atención al colonialismo, la incorporación de la aportación africana, asociaciones con más de veinte países en África y la estrecha colaboración con la diáspora africana en Bélgica.

En Suiza, el Museo Etnográfico de Neuchâtel ha organizado durante décadas exposiciones innovadoras que descentralizaban la autoridad etnográfica y se interrogaban por las bases éticas, filosóficas y políticas de la recolección en el campo, las colecciones de arte, las estrategias museísticas entre otras cuestiones. Los catálogos para un asombroso desfile de exposiciones, desde "Collections Passion» (1982) hasta «Le Musée Cannibale (2003) y aún otras en los años siguientes, constituyen un verdadero archivo del penetrante reflejo de los asuntos abordados en este texto, abriendo y alimentado debates cruciales en cada aspecto de las visiones de la diferencia cultural ${ }^{23}$.

En Inglaterra el reverenciado Museo Pitt Rivers ha organizado un activo programa de artistas residentes y está realizando un esfuerzo especial por incluir

${ }^{23}$ Una presentación de las publicaciones de la MEN, que incluye ensayos de un gran número de autores, puede encontrarse en http://www.men.ch/expositions. 
materiales contemporáneos que impugnen los modos de autenticidad/tradicionalismo de exposiciones del pasado. Y también ha inaugurado un proyecto de investigación que devolverá copias digitales de fotografías actualmente almacenadas en Europa a los descendientes de los aborígenes australianos que son protagonistas de las mismas, proporcionando un enorme recurso sobre la herencia Indígena. Y ha colaborado con el Museo Británico para colocar online más de 6000 fotografías tomadas en el Tibet durante un período de 30 años, con sencillas y amigables funciones que invitan a la participación de forma diversa de los tibetanos (comentarios en las fotos, identificación de individuos, etc.).

En Alemania, la colección del Museo Etnológico de Berlín se prepara para su nueva ubicación en el Humboldt Forum, donde pasará a ocupar dentro de pocos ańos el remodelado palacio prusiano en el centro de la ciudad. Allí, los conservadores han declarado como meta la atención al pasado colonial (incluyendo la violencia) y la historia de las colecciones, a la vez que a la deconstrucción del concepto de «autenticidad» y el rechazo a la idea de culturas «tradicionales» ahistóricas. También apuntan hacia actuales intercambios en lo concerniente a restos humanos y los proyectos de exhibiciones colaborativas con los recursos con las comunidades de origen.

En Italia, el museo Luigi Pigorini en Roma ha estado invitando a diversas partes interesadas a participar de manera activa en la conceptualización y la realización de exposiciones y la organización de coloquios internacionales destinados a explorar el pensamiento vanguardista alrededor de los museos etnográficos. Y el Museo Castello d'Albertis, en Génova ha estado invitando a participar a indígenas del norte y sur de América (Hopi, Cree, Bororo) en sus exhibiciones permanentes, incorporando materiales contemporáneos que desafían las nociones tradicionales de autenticidad, montando exhibiciones centradas en enfoques críticos del pasado colonial y alentando la colaboración entre antropólogos e historiadores del arte. $\mathrm{Al} \mathrm{mismo} \mathrm{tiempo,} \mathrm{los} \mathrm{esfuerzos} \mathrm{de} \mathrm{cara} \mathrm{a} \mathrm{superar} \mathrm{las} \mathrm{tendencias}$ tradicionales a la "primitivización» en el imaginario museístico de su propio país se enfrentan a una ardua y desalentadora batalla; tal y como Giovanna da Passano deja claro en su devastadora evaluación del estado de las aproximaciones italianas al arte y la cultura africanas (2010), muchos museos italianos están (como muchos otros en Francia ${ }^{24}$ ) aún fuera de onda con la serie de acontecimientos en otras partes del mundo que han sido el objeto de este ensayo.

24 Véase De l’Estoile, 2007; Price, 2007 y Murphy, 2009:14-15. Tan reciente como en 2011, un catálogo publicado por el Museo Quai Branly representaba el colonialismo francés 


\section{Bibliografía}

Ames, M. (1992). Cannibal Tours and Glass Boxes: The Anthropology of Museums. Vancouver: UBC Press.

Appiah, K. (2006). "Whose Culture Is It?» New York Review of Books, 9 February, pp. 38-41.

Arnoldi, M. (2005). "African Voices: A Dynamic Collaboration Between the Museum and Its Communities», en Representing African Art and Cultures, Y. Kawaguchi \& K. Yoshida (eds.), Senri Ethnological Reports 54, pp. 79-92.

Broom, H. (1994). The Western Canon: The Books and School of the Ages. New York: Harcourt.

Bolton, R. (ed.). (1992). Culture Wars: Documents from the Recent Controversies in the Arts. New York: The New Press.

Brown, M. (2003). Who Owns Native Culture? Cambridge MA: Harvard University Press.

Clifford, J. (1988). The Predicament of Culture: Twentieth-Century Ethnography, Literature, and Art. Cambridge MA: Harvard University Press.

- (1991). "The transit lounge of culture» (review of The Imam and the Indian by Amitav Ghosh). Times Literary Supplement, Friday, May 03, pp. 7-8.

- (1997). Routes: Travel and Translation in the Late Twentieth Century. Cambridge MA: Harvard University Press.

- (2012). Feeling Historical. Cultural Anthropology 27/3:417-426.

Clifford, J. \& G. E. Marcus (eds.). (1986). Writing Culture: The Poetics and Politics of Ethnography. Berkeley: University of California Press.

Drewal, H. \& M. Drewal. (1983). Gelede: Art and Female Power. Bloomington IN: Indiana University Press.

Fox, Richard G. (1991). «Introduction: Working in the Present», en Richard G. Fox (ed.), Recapturing Anthropology: Working in the Present, Santa Fe NM: School of American Research, pp. 1-16.

Gómez Peña, G. (2001). The New World Border: Prophesies, Poems and Loqueras for the End of the Century. San Francisco CA: City Lights Publishers.

como el esfuerzo en gran medida generoso para liberar a los africanos del estado de caos y la brutalidad (Leloup, 2011:65). James Clifford (2012:418-419) mantiene una provisional brizna de esperanza a que «quizás» Francia entre en razón. 
González, R. (2008). "Human Terrain: Past, Present and Future Applications.» Anthropology Today 24(1):21-26.

Gordon, C. \& F. Silva. (2005). «Objetos vivos: a curadoria da coleção etnográfica Xikrin-Kayapó no Museu de Arqueologia. Estudos Históricos 36:93-110.

Harris, C. \& M. O’Hanlon. (2013). «The Future of the Ethnographic Museum». Anthropology Today 29 (1): 8-12.

Hymes, D. (ed.). (1969). Reinventing Anthropology. New York: Pantheon.

Jonaitis, A. (ed.). (1991). Chiefly Feasts: The Enduring Kwakiutl Potlatch. Seattle: University of Washington Press.

Karp, I. \& S. Lavine, (eds.). (1991). Exhibiting Cultures: The Poetics and Politics of Museum Display. Washington DC: Smithsonian Books.

Karp, I., Ch. Kreamer \& S. Lavine (eds.). (1992). Museums and Communities: The Politics of Public Culture. Washington DC: Smithsonian Books.

Karp, I., C. Kratz, L. Szwaja \& T. Frausto (eds.). (2006). Museum Frictions: Public Cultures/Global Transformations. Durham NC: Duke University Press.

Kirshenblatt-Gimblett, B. (1998). Destination Culture: Tourism, Museums, and Heritage. Berkeley CA: University of California Press.

Косн, C. (1998). «The Contest for American Culture: A Leadership Case Study on The NEA and NEH Funding Crisis.» http://www.upenn.edu/pnc/ptkoch.html [Consultado por última vez el 17 de Julio de 2012]

Krech, S. (1994). «Museums, Voices, Representations.» Museum Anthropology 18(3):3-8.

Leloup, H. (2011). Dogon. Paris: Somogy/musée du quai Branly.

De L'Estoile, B. (2007). Le goût des autres: de l'exposition coloniale aux arts premiers. Paris: Flammarion.

Lippard, L. (1990). Mixed Blessings: New Art in a Multicultural America. New York: Pantheon.

- (1999). "Too Political? Forget It», en Brian Wallis, Marianne Weems \& Philip Yenawine (eds.), Art Matters: How the Culture Wars Changed America. New York: New York University Press, pp. 39-61.

Marcus, G. \& F. Myers (eds.). (1995). The Traffic in Culture: Refiguring Art and Anthropology. Berkeley CA: University of California Press.

Morrison, T. (1987). Beloved. New York: Alfred A. Knopf.

Mosquera, G. (1994). «Some Problems in Transcultural Curating», en Global Visions: Towards a New Internationalism in the Visual Arts. Jean Fisher (ed.), London: Kala Press, pp. 133-139. 
Murphy, M. (2009). De l'imaginaire au musée: Les arts d'Afrique à Paris et à New York (1931-2006). Dijon: Les Presses du Réel.

Da Passano, M. (2010). «Between Cultural Lag and Confusion: The Reception of African Art in Italy.» African Arts 43(2):9-14.

Phillips, R. (2011). Museum Pieces: Towards the Indigenization of Canadian Museums. Montreal: McGill-Queen's University Press.

Phillips, R., y C. B. Steiner. (1999). Unpacking Culture: Art and Commodity in Colonial and Postcolonial Worlds. Berkeley CA: University of California Press.

Price, R. (1983). First-Time: The Historical Vision of an Afro-American People. Baltimore MD, Johns Hopkins University Press.

Price, S. (1989). Primitive Art in Civilized Places. Chicago, University of Chicago Press. [Arte primitivo en tierra civilizada. Mexico: Siglo Veintiuno, 1993]

- (2007). Paris Primitive: Jacques Chirac's Museum on the Quai Branly. Chicago, University of Chicago Press. [Au musée des illusions: le rendez-vous manqué du quai Branly. Paris: Éditions Denoël, 2011]

Rabinow, P. (1977). Reflections on Fieldwork in Morocco. Berkeley: University of California Press.

Rosaldo, R. (1980). Ilongot Headhunting, 1888-1974: A Study in Society and History. Stanford CA: Stanford University Press.

Rothfield, L. (2001). Unsettling «Sensation»: Arts-Policy Lessons from the Brooklyn Museum of Art Controversy. New Brunswick NJ: Rutgers University Press.

Sherman, D. (2011). French Primitivism and the Ends of Empire, 1945-1975. Chicago: University of Chicago Press.

Stocking, G. (1992). The Ethnographer's Magic and Other Essays in the History of Anthropology. Madison: University of Wisconsin Press.

Sturtevant, W. (1959). «A Technique for Ethnographic Note-Taking», American Anthropologist 61:677-678.

Taussig, M. (1987). Shamanism, Colonialism, and the Wild Man. Chicago: University of Chicago Press.

Tedlock, B. \& D. Tedlock. (1995). «From the Editors», American Anthropologist 97: 8-9.

Tucker, M. (ed.). (1992). Different Voices: A Social, Cultural, and Historical Framework for Change in the American Art Museum. New York: Association of Art Museum Directors.

Walker, R. (1994). "Anonymous has a Name», en The Yoruba Artist: New Theoretical Perspectives on African Arts, Rowland Abiodun, Henry J. Drewal, \& John Pemberton III (eds.). Washington DC: Smithsonian Institution Press, pp. 90-106. 
Wolf, E. (1982). Europe and the People Without History. Berkeley: University of California Press.

Yenawine, P. (1999). "But What Has Changed?», en Brian Wallis, Marianne Weems \& Philip Yenawine (eds.), Art Matters: How the Culture Wars Changed America. New York: New York University Press, pp. 9-23.

Recibido 5/10/2012

Aceptado 9/12/2012 